\title{
Influence of Roll Bending on Center Segregation in Continuously Cast Slabs
}

\author{
Shigeaki OGIBAYASHI, Mamoru YAMADA, ${ }^{1)}$ Yuzuru YOSHIDA ${ }^{2)}$ and Tatsuo MUKAl'
}

Steelmaking Process, Process Technology Research Laboratories, Nippon Steel Corporation, Shintomi, Futtsu, Chibaken, 299-12 Japan. 1) Steelmaking Technical Division, Nippon Steel Corporation, Otemachi, Chiyoda-ku, Tokyo, 100-71 Japan. $\quad$ 2) Kimitsu R \& D Laboratory, Nippon Steel Corporation, Kimitsu, Kimitsu, Chiba-ken, $299-11$ Japan. 3) New Materials Division, Nippon Steel Corporation, Otemachi, Chiyoda-ku, Tokyo, 100-71 Japan.

(Received on July 29, 1991; accepted in final form on September 20,1991)

\begin{abstract}
The influence of roll bending on center segregation in continuously cast slabs was studied by conducting the test in which roll bending was controlled during casting. The behavior of roll bending and center segregation in sequential casting were also investigated. As a result, it was clarified that (1) variations in center segregation in the casting direction are attributable to roll bending and center segregation deteriorates with increasing roll bending, (2) the amount of roll bending increases up to $1.7 \mathrm{~mm}$ during casting, as a result of which variations in center segregation in the casting direction are increased and segregation deteriorates with increasing number of cast heats in sequential casting, and (3) the use of divided rolls in the final stage of solidification is effective in decreasing roll bending and keeping center segregation at lower level. Of all mechanical factors, roll bending was estimated to be the largest factor for deterioration of center segregation in the case of casting employing one-piece rolls of conventional type.
\end{abstract}

KEY WORDS: continuous casting; slab; center segregation; bulging between rolls; roll bending; one-piece roll; divided roll; sequential casting; steel.

\section{Introduction}

So far, many researchers ${ }^{1,2)}$ have reported that center segregation in continuously cast slabs is greatly affected by various mechanical factors. However, the contributions of these factors to center segregation have not been fully elucidated. The mechanical factors affecting center segregation include slab bulging between rolls, roll misalignment, roll bending, roll wear, roll and frame deflection, backlash in the mechanical system, etc. Considerable research has been conducted on the influence of slab bulging between rolls, ${ }^{3,4)}$ but little systematic work has been directed toward the effects of other factors. Asano et al. ${ }^{2)}$ and other researchers ${ }^{5,6)}$ reported the variations in center segregation in the casting direction, which suggests the influence of roll bending, and Perkins et al. ${ }^{78)}$ investigated the behavior of roll bending itself, but they did not specify the reason of the cause of variations in center segregation in the casting direction, distinguishing the influence of other factors such as roll misalignment and slab bulging.

The authors experimentally proved that variations in center segregation in the casting direction are attributable to roll bending. Based on the results thus obtained, the present report discusses the contributions of various mechanical factors to center segregation.

\section{Test Methods}

2.1. Investigation of Roll Bending and Variations in Center Segregation in the Casting Direction

Roll bending and variations in center segregation in the casting direction were investigated at No. 2 continuous caster in Kimitsu Works. The main specification of this caster is given in Table 1 . The reduction gradient of rolls in the segments in the straightening and horizontal zone (\#7-\#10 segments in the range from 15.0 to $23.6 \mathrm{~m}$ from the meniscus) was adjusted

Table 1. Main specifications of continuous caster,

\begin{tabular}{lll}
\hline \multicolumn{1}{c}{ Items } & \multicolumn{1}{c}{ No. 2 caster } & No. 1 caster \\
\hline Machine type & $\begin{array}{l}\text { Vertical bending type } \\
\text { (V.L. }=2.5 \mathrm{~m})\end{array}$ & Bow type \\
Slab size & $\begin{array}{l}210,240,300 \mathrm{~mm} \\
\times 980-2300 \mathrm{~mm}\end{array}$ & $210,240 \mathrm{~mm}$ \\
& 2 & $\times 960-2200 \mathrm{~mm}$ \\
Number of strands & $9.0 \mathrm{~m}$ & 2 \\
Machine radius & 5 (bending), & $10.5 \mathrm{~m}$ \\
No. of bending and & (straightening) \\
straightening points & 4 (straightening) & \\
Segment or roll No. at & $\# 7, \# 8$ seg. $(15.0-19.3 \mathrm{~m}$ & $\# 42$ roll (16.7 m \\
straightening points & from meniscus) & from meniscus) \\
Machine length & $34.3 \mathrm{~m}$ & $22.8 \mathrm{~m}$ \\
Roll pitch in & $435 \mathrm{~mm}$ & $550 \mathrm{~mm}$ \\
horizontal zone & & 250 \\
Heat size (ton/heat) & 305 & \\
\hline
\end{tabular}


Table 2. Casting conditions in the test conducted at Kimitsu No. 2 caster with conventional one-piece rolls.

\begin{tabular}{cccccccccccc}
\hline & \multicolumn{4}{c}{ Chemical composition in tundish (wt \%) } & & Slab size \\
$(\mathrm{mm})$ & $\begin{array}{c}\text { Casting } \\
\text { speed } \\
(\mathrm{m} / \mathrm{min})\end{array}$ & $\begin{array}{c}\text { Specific } \\
\text { water ratio } \\
(l / \mathrm{kg})\end{array}$ & $\begin{array}{c}\text { Casting } \\
\text { temp. } \\
\left({ }^{\circ} \mathrm{C}\right)\end{array}$ & $\begin{array}{c}\text { EMS } \\
\mathrm{C}\end{array}$ & $\mathrm{Si}$ & $\mathrm{Mn}$ & $\mathrm{P}$ & $\mathrm{S}$ & $\mathrm{Al}$ & & \\
\hline $0.12-0.18$ & $0.13-0.19$ & $0.69-0.98$ & $0.017-0.023$ & $0.005-0.011$ & $0.016-0.028$ & $210 \times 1480$ & $1.26-1.30$ & $0.79-0.90$ & $1534-1554$ & Not applied \\
\hline
\end{tabular}

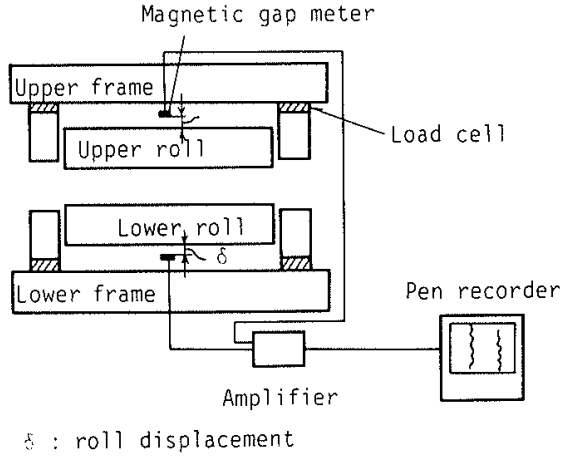

Fig. 1. Measuring method of roll bending and roll reaction force during casting.

to $0.25 \mathrm{~mm} / \mathrm{m}$ in advance and sequential castings were performed in which 19 heats were sequentially cast in maximum. The reduction gradient shown above nearly corresponds to the thermal shrinkage at the slab edges. The rolls used were the one-piece rolls of conventional type. The casting conditions are shown in Table 2. The behavior of roll bending was investigated by measuring the displacement and reaction force of rolls in the horizontal and straightening zones during casting, according to the method shown in Fig. 1.

Then, in order to investigate the effect of the decrease in roll bending on center segregation, 3 segments with divided rolls were experimentally installed in the horizontal zone of No. 2 continuous caster (\#9-\#11 segments on the second strand side: in the range of 19.3 to $25.8 \mathrm{~m}$ from the meniscus) and roll bending and center segregation were investigated, the results of which were compared with those obtained from the slabs cast with one-piece rolls in the same heats. The main specifications of this divided roll segments and the casting conditions in the test employing divided roll segments are given in Tables 3 and 4, respectively.

In these tests, the casting speed was determined depending on the slab thickness and secondary cooling condition so that the crater end determined by the pin shooting method ${ }^{9)}$ came at the exit side of $\# 10$ segment, and the slabs cast at the completely uniform casting speed from the meniscus up to the crater end were used as test samples for the investigation of center segregation. In the test employing the divided rolls, thermocouples were embedded immediately below the roll surface to analyze the mechanism of the formation of roll bending.

\subsection{Roll Bending Control Test}

Load cells were installed at the 3 rolls (\#35, \#36 and \#37 rolls) in the horizontal zone of Kimitsu No. 1 continuous caster. The bending of the rolls was decreased or increased during casting by intermittently spraying water to the rolls in response to periodic variations in
Table 3. Main specifications of divided roll segment.

\begin{tabular}{lcc}
\hline \multicolumn{1}{c}{ Roll type } & Conventional roll & Divided roll \\
\hline Number of divisions & One piece & Three pieces \\
Roll diameter & $405 \mathrm{~mm}$ & $330 \mathrm{~mm}$ \\
Roll pitch & $435 \mathrm{~mm}$ & $362.5 \mathrm{~mm}$ \\
Number of rolls & 5 pairs $/ \mathrm{seg}$. & 6 pairs $/ \mathrm{seg}$. \\
Number of traverse & 3 pairs/seg. & 6 pairs $/ \mathrm{seg}$. \\
\hline
\end{tabular}

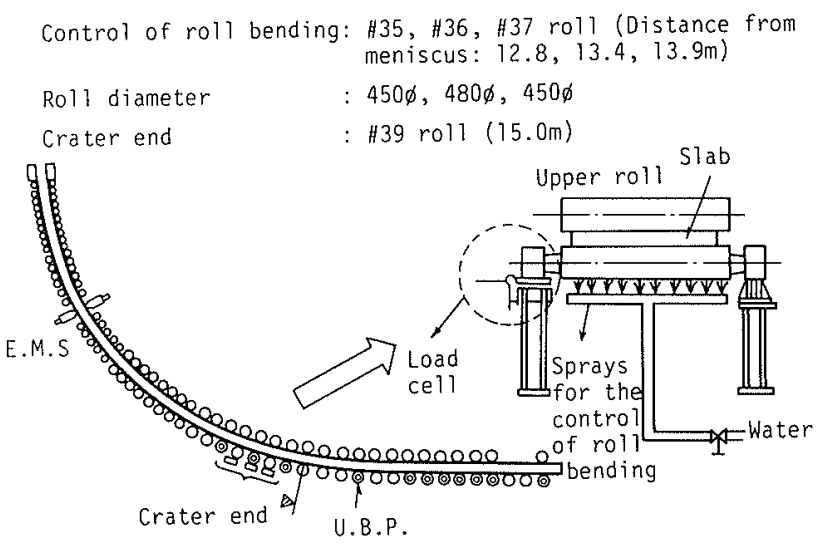

Fig. 2. Outline of roll bending control test.

roll reaction force, and the relationship between center segregation and roll bending was investigated. The casting speed was determined so that the crater end determined by the pin shooting method ${ }^{9)}$ came at \#39 roll. The main specification of No. 1 continuous caster is given in Table 1 in comparison with that of No. 2 caster. The casting conditions employed in this test are given in Table 5 and the test procedure is schematically shown in Fig. 2. Roll bending is decreased by intermittently spraying water from the bottom to the lower rolls when the roll reaction force is minimal, but is increased by spraying water when the roll reaction force is maximal. Samples were cut from the longitudinal cross section at the part of the slab which was cast during the time when roll bending was controlled, and the relationship between center segregation and roll bending was analyzed.

\subsection{Evaluation Method of Center Segregation}

In the tests described above, sulfur prints and etch prints ${ }^{10)}$ were taken for about $2 \mathrm{~m}$ corresponding to one rotation of the roll in order to investigate center segregation. The center segregation was evaluated at intervals of $100 \mathrm{~mm}$ throughout the entire length of the samples according to the center segregation rating method. ${ }^{2)}$ In this method, center segregation is rated from 0 to 4 depending on the thickness of the segregation line and classified into $A$ to $C$ types depending on the type 
Table 4. Casting conditions in the test employing divided roll segments.

\begin{tabular}{|c|c|c|c|c|c|c|c|c|c|c|}
\hline \multicolumn{6}{|c|}{ Chemical composition (wt \%) } & \multirow{2}{*}{$\begin{array}{l}\text { Casting } \\
\text { speed } \\
(\mathrm{m} / \mathrm{min})\end{array}$} & \multirow{2}{*}{$\begin{array}{c}\text { Specific } \\
\text { water ratio } \\
(l / \mathrm{kg})\end{array}$} & \multirow{2}{*}{$\begin{array}{l}\text { Thickness/ } \\
\text { width } \\
(\mathrm{mm})\end{array}$} & \multirow{2}{*}{$\begin{array}{c}\Delta T \\
\left({ }^{\circ} \mathrm{C}\right)\end{array}$} & \multirow{2}{*}{ EMS } \\
\hline $\mathrm{C}$ & $\mathrm{Si}$ & $\mathrm{Mn}$ & $\mathrm{P}$ & $\mathrm{S}$ & Others & & & & & \\
\hline $0.05-0.10$ & $0.10-0.50$ & $1.0-1.5$ & $0.004-0.011$ & $0.0007-0.0025$ & $\begin{array}{l}\mathrm{Cu}, \mathrm{Ti}, \mathrm{V} \\
\mathrm{Nb}, \mathrm{Ni}, \mathrm{Ca}\end{array}$ & $0.9-1.2$ & $0.4-0.7$ & $\begin{array}{l}210-240 / \\
\text { I } 500-220\end{array}$ & $10-30$ & $\begin{array}{c}\text { Without } \\
\text { EMS }\end{array}$ \\
\hline
\end{tabular}

Table 5. Casting conditions in roll bending control test.

\begin{tabular}{|c|c|c|c|c|c|c|c|c|c|}
\hline \multicolumn{6}{|c|}{ Chemical composition (wt \%) } & \multirow{2}{*}{$\begin{array}{l}\text { Casting speed } \\
(\mathrm{m} / \mathrm{min})\end{array}$} & \multirow{2}{*}{$\begin{array}{c}\text { Specific } \\
\text { water ratio } \\
(l / \mathrm{kg})\end{array}$} & \multirow{2}{*}{$\begin{array}{c}\text { Slab size } \\
(\mathrm{mm})\end{array}$} & \multirow{2}{*}{$\begin{array}{c}\Delta T \\
\left({ }^{\circ} \mathrm{C}\right)\end{array}$} \\
\hline $\mathrm{C}$ & $\mathrm{Si}$ & $\mathrm{Mn}$ & $P$ & $S$ & A] & & & & \\
\hline 0.22 & 0.32 & 0.71 & 0.02 & 0.02 & 0.025 & 0.95 & 1.15 & $210 \times 1560$ & 12 \\
\hline
\end{tabular}

of segregation. Namely, the slab which is free from center segregation receives the index 0 , and the index 4 is given if the thickness of segregation line is about $4 \mathrm{~mm}$. The continuous type center segregation is classified as type $\mathrm{A}$ and the spot-like center segregation, as type C. Type $\mathrm{B}$ is the type in which both continuous and spot-like types of segregation are present in a mixed manner. The intermediate types between these three types are classified as types $\mathrm{AB}$ and $\mathrm{BC}$.

Though the segregation rating method is a simple evaluation method, the results obtained by this method agree well with the segregation degrees determined by the step slicing and analysis method in which chemical analysis is made for an incremented set of metal shavings taken from the vicinity of the slab center and the evaluation indices obtained by CMA (Computer Aided Microanalyzer). ${ }^{11,12)}$

For the slabs which were cast employing the divided rolls, the segregation area ratios of $\mathrm{Mn}$ and $\mathrm{P}$ detected by CMA and the thickness of the segregation line in the rolled plate on etch print ${ }^{10)}$ were also investigated. The investigation of segregation by CMA was conducted for the longitudinal cross section of the slab of $20 \mathrm{~mm} \times$ $40 \mathrm{~mm}$ in area, including the mid-thickness part. The diameter of the beam used was $50 \mu \mathrm{m}$.

\section{Results of Tests and Discussion}

\subsection{Behavior of Roll Bending during Casting}

Figure 3 shows a typical example of variations in roll reaction force and roll displacement with time during casting with one-piece rolls which were measured at Kimitsu No. 2 continuous caster. The roll reaction force periodically varies with a period corresponding to one rotation of the roll. Similarly, the roll displacement periodically varies at the center of its barrel length in response to variations in roll reaction force. This tendency is, more or less, observed under all operating conditions in the case of casting with one-piece rolls. As the lengthwise period of such variations coincides with the circumference of the roll, it is apparent that these variations are caused by roll bending. ${ }^{7,8)}$ As shown in Fig. 4, the amount of roll bending gradually increases with time after the start of casting but remains nearly unchanged after the lapse of a certain time. After the

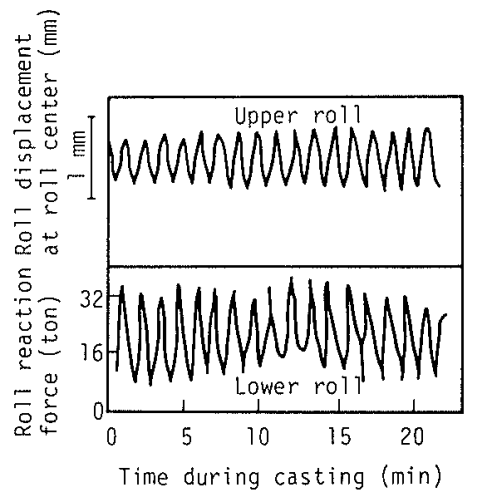

Fig. 3. Periodic variations in roll displacement and roll reaction force.

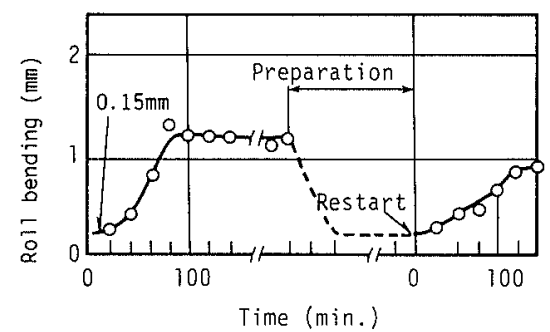

Fig. 4. Chronological change in roll bending during casting.

end of casting, roll bending decreases with decreasing roll temperature, returning to the amount of initial bending of about $0.15 \mathrm{~mm}$.

Figure 5 shows changes in roll bending before and after tundish exchange. The amount of roll bending becomes particularly large when casting is stopped due to tundish exchange or for any other reasons. The amount of roll bending increases during the stoppage of casting, and variations in roll reaction force after such stoppage become greater than those before the stoppage. A closer look at Fig. 5 reveals that there is such time when changes in roll displacement with time become slow even during the withdrawal of slab. Such slow variations indicate that the rolls are slipping.

To statistically evaluate the amount of roll bending in the casting employing one-piece roll segments, the amount of roll bending was measured for 6 consecutive heats, the results of which are shown in Fig. 6. It will be seen from Fig. 6 that the average amount of roll bending is $0.8 \mathrm{~mm}$, the maximum amount being $1.7 \mathrm{~mm}$. The 
frequency with which roll bending in excess of $1.6 \mathrm{~mm}$ occurs is about $10 \%$.

In the case of the segments employing the divided rolls, on the other hand, the maximum amount of roll bending is $0.2 \mathrm{~mm}$ as shown in Fig. 7 and the average amount

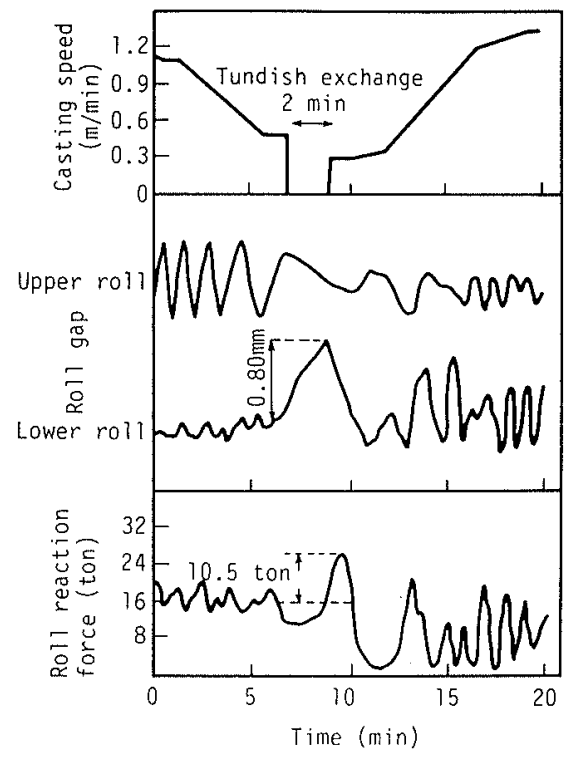

Fig. 5. Behavior of roll bending before and after tundish exchange.

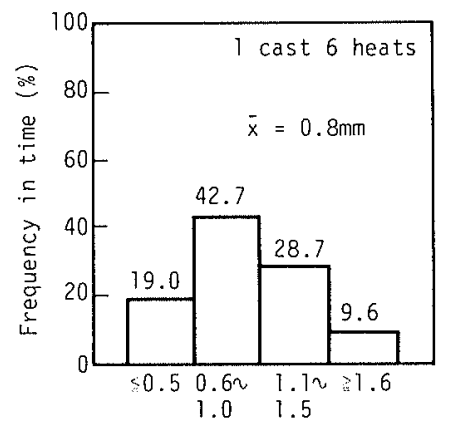

Amplitude of roll bending (mm)

Fig. 6. Distribution of the amplitude of roll bending. was $0.1 \mathrm{~mm}$.

\subsection{Relationship between Roll Bending and Center Segregation}

To examine the relationship between roll bending and center segregation, roll bending control test was conducted at No. 1 continuous caster in Kimitsu Works. Variations in roll reaction force during the casting for each controlling level of roll bending are shown in Fig.

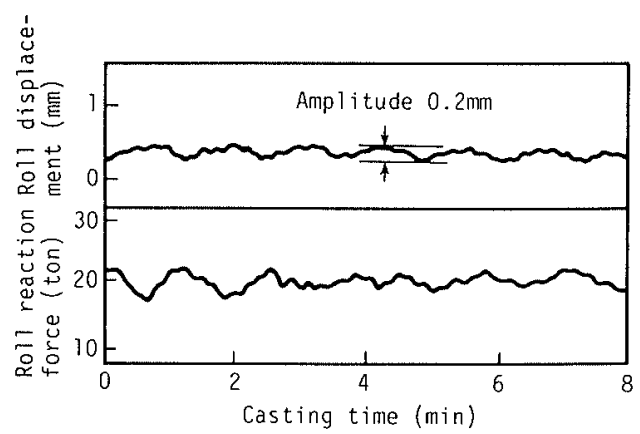

Fig. 7. Variations in roll displacement and roll reaction force during casting with divided roll segment.

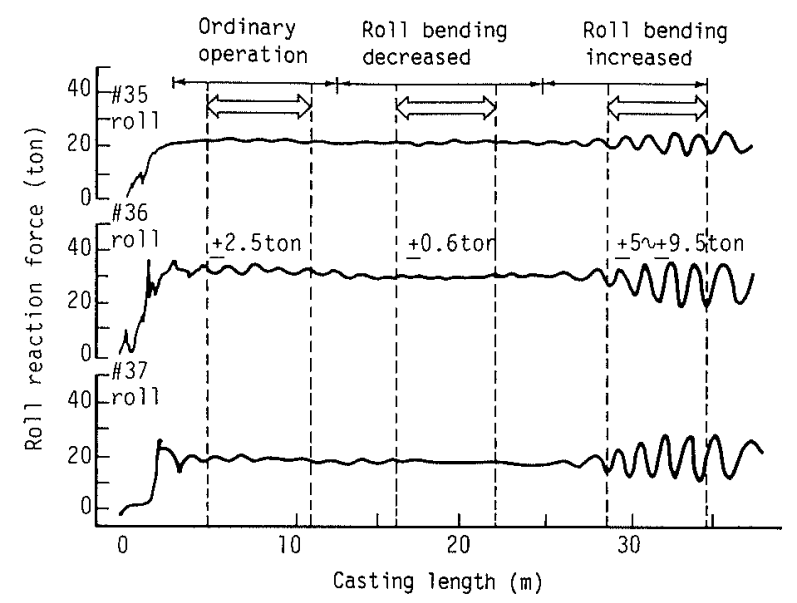

Fig. 8. Periodic variations in roll reaction force observed in the roll bending control test.

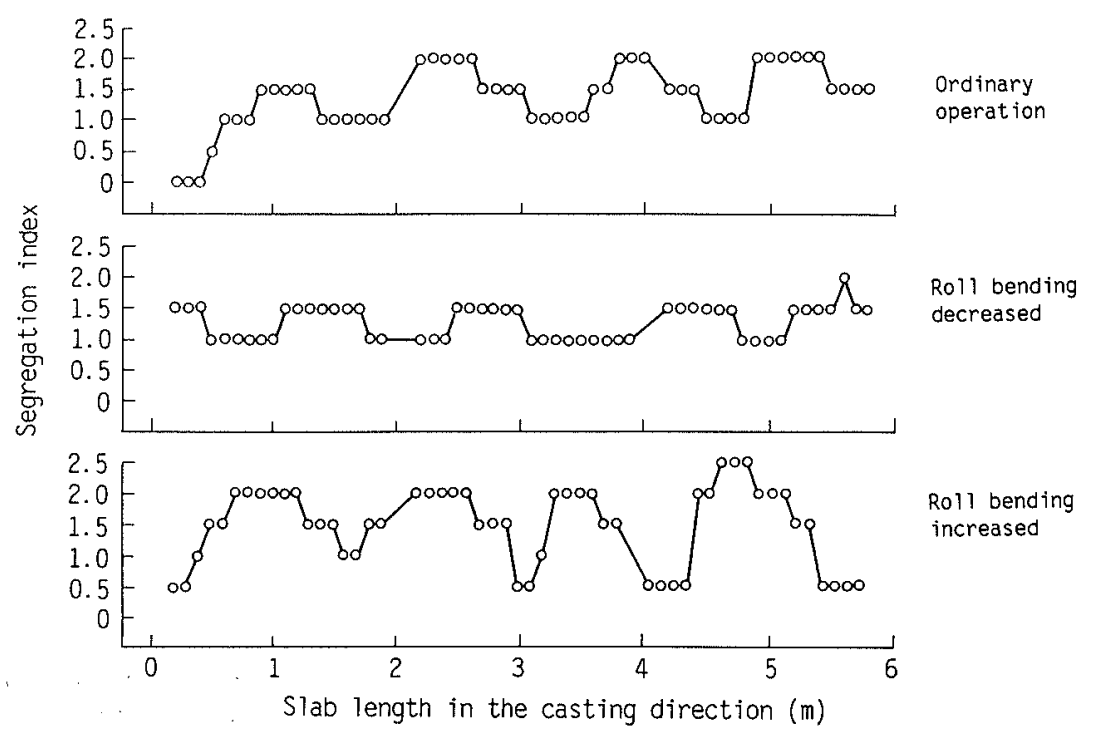

Fig. 9. Variations in center segregation at mid-width of slab in the casting direction observed in roll bending control tesi. 


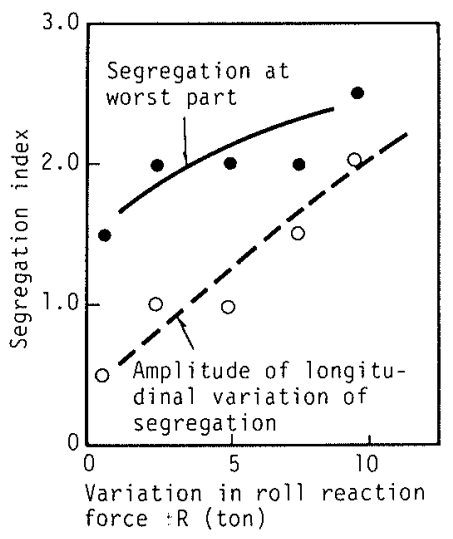

Fig. 10 Relationship between center segregation index and variation in roll reaction force.

$\mathbf{8}$, while variations in center segregation at the mid-width of slab in the casting direction are shown in Fig. 9 in relation to the controlling levels of roll bending. When roll bending was increased by spraying water so as to increase the temperature unevenness along the circumference of roll, variations in roll reaction force are increased and significant periodic variations in center segregation are observed. When roll bending was decreased, on the other hand, periodic variations in center segregation are suppressed in response to decreases in roll reaction force.

The results described above are summarized in Fig. 10. A clear correlation is observed between variations in roll reaction force and variations in center segregation, and the segregation index at the worst part increases with increasing variations in segregation. The period of variations in center segregation is mostly distributed between 1.3 and $1.6 \mathrm{~m}$ as shown in Fig. 11, which almost agrees with the period of rotation of the rolls ( $\# 35$ and \#37 rolls: $1.41 \mathrm{~m}, \# 36$ roll: $1.51 \mathrm{~m}$ ).

As described above, a clear correlation was observed between roll bending and center segregation. It was, therefore, confirmed that periodic variations in center segregation are caused by roll bending, and that roll bending is a large factor for deterioration of segregation in the case of casting employing one-piece rolls.

\subsection{Influence of Roll Shape on Center Segregation}

3.3.1. Variations in Center Segregation in the Longitudinal Direction in the Casting Employing One-piece Rolls

Figure 12 shows the changes in variations in center segregation in the longitudinal direction with increasing number of cast heats in sequential casting. Figure 13 shows the relationship between the number of cast heats and the maximum and average center segregation indices measured at intervals of $100 \mathrm{~mm}$ in the casting direction in each heat. When casting is conducted by using the one-piece rolls of conventional type, center segregation is periodically varied in the casting direction and the amplitude of such variations increases with increasing number of cast heats in sequential casting. From the results described in Sec. 3.2, it is apparent that such variations in center segregation are attributable to roll bending. As the amount of roll bending is small in the

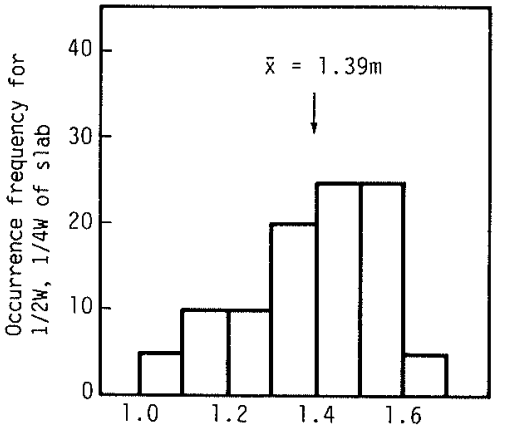

A period of longitudinal variation in segregation index $(\mathrm{m})$

Fig. 11. Frequency of the period of longitudinal variation in center segregation.
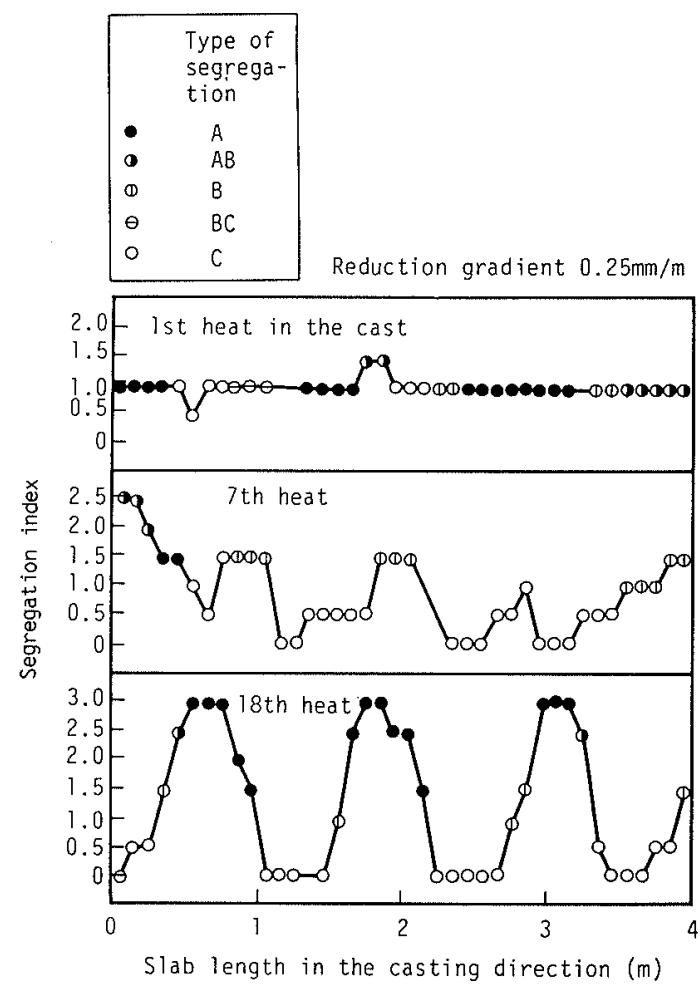

Fig. 12. Changes in the longitudinal variation in center segregation at mid-width of slab with increasing number of cast heats in sequential casting.

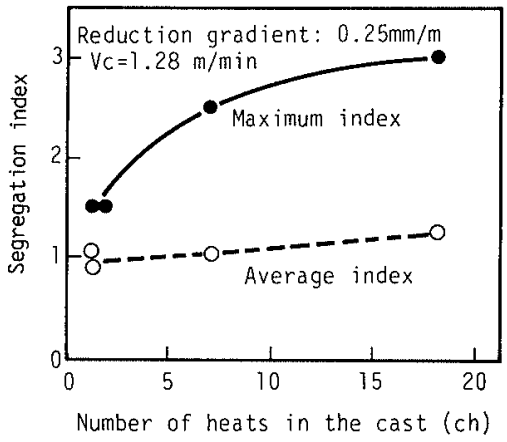

Fig. 13 Relationship between center segregation and number of cast heats in sequential casting.

early stage of sequential casting, variations in center segregation are small. With increasing number of cast heats, the amplitude of variations in center segregation increases, probably because roll bending is enlarged due 
to the increase in roll temperature and temporary stoppage of withdrawal in the case of sequential casting of different steel grades.

3.3.2. Variations in Center Segregation in the Longitudinal Direction in the Casting Employing Divided Rolls

Figure 14 shows an example of the distribution of center segregation indices in the longitudinal direction in the casting employing divided rolls. For the purpose of comparison, the index distribution in the slabs cast employing one-piece rolls in the same heat are also shown in Fig. 14. While the center segregation indices of the slabs cast with one-piece rolls are widely varied from 0 to 2.0 , the segregation indices of the slabs cast with divided rolls under the same casting conditions are distributed within $0.5-1.0$, evidencing that periodic variations in segregation were suppressed by the use of

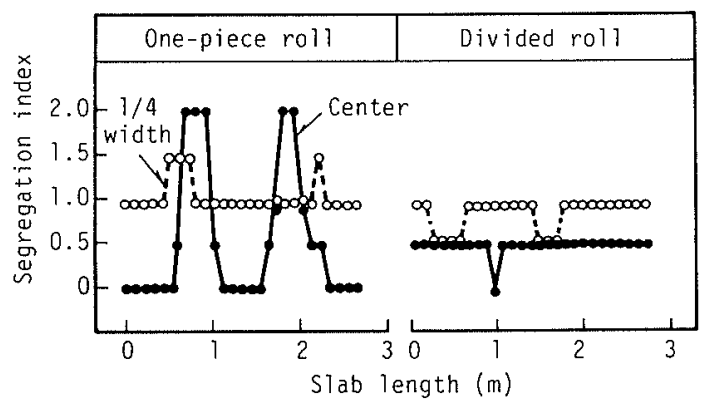

Fig. 14. Effect of divided rolls on the longitudinal variations in center segregation.

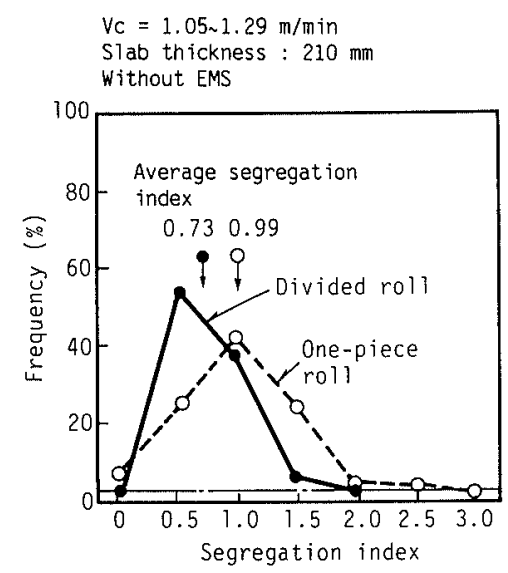

Fig. 15. Effect of divided rolls on the occurrence frequency of center segregation index of slab.

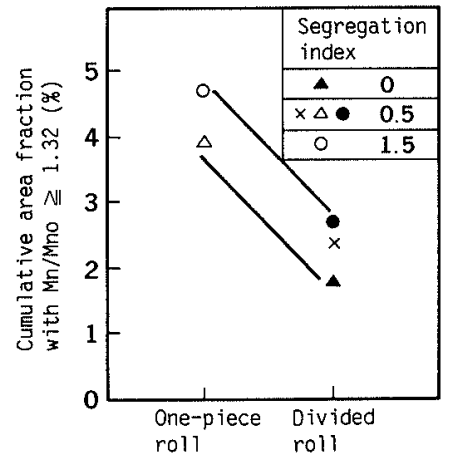

divided rolls.

To quantitatively evaluate the effect of divided rolls on the improvement of segregation in a series of test heats, the segregation index obtained at intervals of $100 \mathrm{~mm}$ in the casting direction was taken as one data and the occurrence frequency with which each segregation index occurs was determined from several hundreds of data. The segregation indices thus determined were statistically compared between the slabs cast with divided rolls and those cast with one-piece rolls. The results of this comparison are shown in Fig. 15. It will be noted that the segregation index was improved by about 0.3 on the average by the use of divided rolls. The occurrence frequency with which the indices larger than 1.5 occur was decreased from 25 to $5 \%$, about one-fifth of the frequency in the slabs cast with one-piece rolls. This result indicates that the indices of $0.5-1.0$ could be stably obtained by the use of divided rolls. As shown in Fig. 16, the segregation area ratios of $\mathrm{Mn}$ and $\mathrm{P}$ determined by CMA were also considerably improved by the use of divided rolls.

The effect of divided rolls on the improvement of product quality was evaluated in terms of the thickness of segregation line in the heavy plate. As shown in Fig. 17, the average thickness of segregation line in the plate rolled from the slab cast with divided rolls was about half of that in the plate rolled from the slab cast with one-piece rolls. In the case of the plate rolled from the slab cast with divided rolls, variations in segregation in the plate were also reduced to a lower level and segregation lines thicker than $0.3 \mathrm{~mm}$ in particular were hardly observed. The decrease in the thickness of segregation line in the plate by the use of divided rolls agrees well with the effect of divided rolls on the decrease in segregation index of the slab.

\subsection{Mechanism of the Formation of Roll Bending and Its Influence on Center Segregation}

Figure 18 shows the roll temperatures measured during casting by means of the thermocouples embedded below the roll surface. It will be noted that the temperature below the roll surface is changed periodically in response to the rotation of the rolls, reaching the highest value when the measuring point is in contact with the slab. The comparison of the highest temperatures measured at the two opposite points on the circumference of the roll (points $\mathrm{A}$ and $\mathrm{B}$ ) reveals a difference of $35^{\circ} \mathrm{C}$, i.e., temperature unevenness. Roll displacement changes in

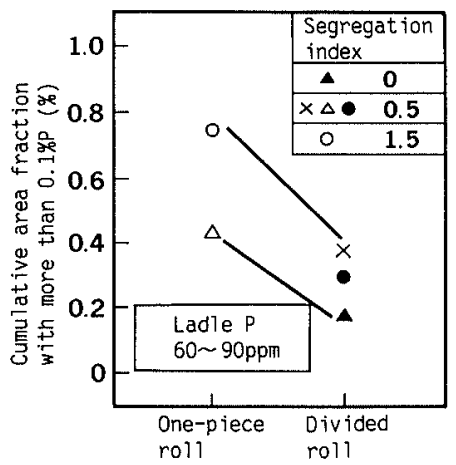

Fig. 16. Effect of divided rolls on the manganese and phosphorus segregation observed by CMA. 


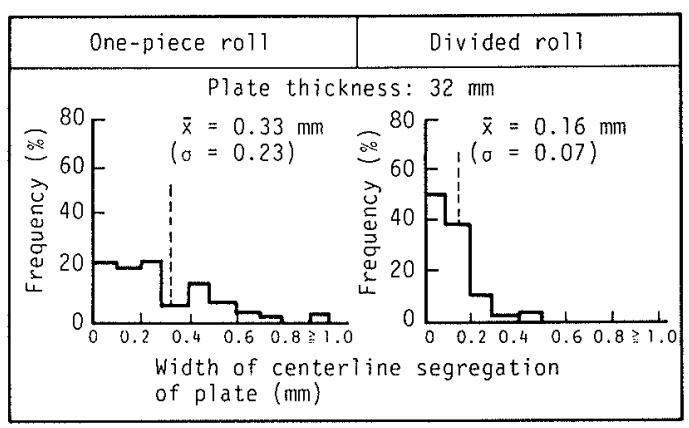

Fig. 17. Comparison of macro segregation of plate between one-piece and divided roll.

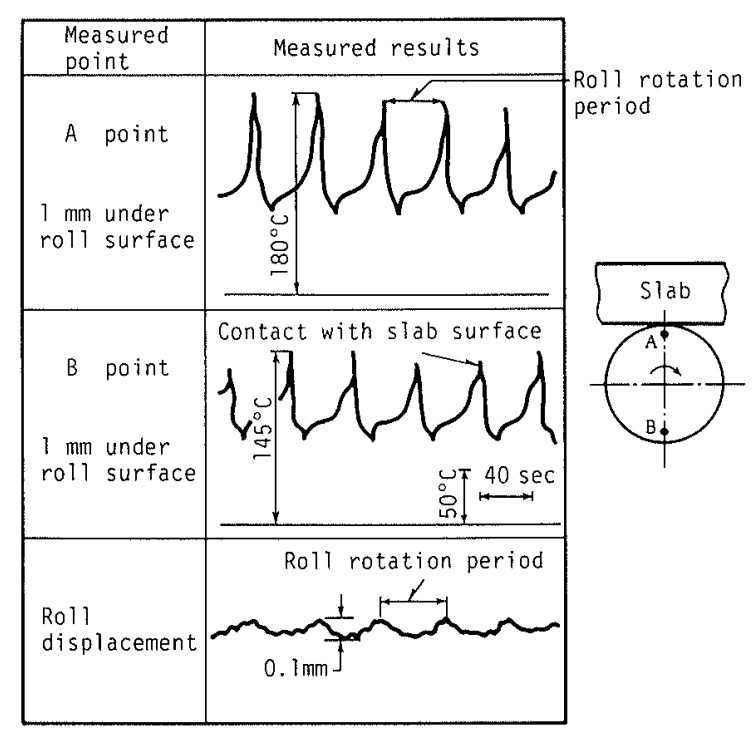

Fig. 18. Correspondence between periodic variation in roll displacement and variation in subsurface temperature of roll.

response to higher temperature side (point $\mathrm{A}$ ), indicating that temperature unevenness is the cause of roll bending.

From these results of measurement, the formation mechanism of roll bending is considered as described below. The occurrence of roll bending can be discussed by dividing it into the occurrence of bending caused in the early stage of casting, i.e., initial bending, and the increase in bending during casting. When new rolls are used, the most probable cause of initial roll bending is the difference to be caused in thermal history in the circumferential direction of the roll which is resulted during casting from the release of the residual stress developed at the time of roll fabrication by heat or non-steady withdrawal due to subsequent variations in casting speed or stoppage of casting. When used rolls are employed, the residual roll bending remained after the casting conducted before corresponds to the initial bending. Once the roll is bent, the contact length of roll with the slab on the convex side (higher temperature side) of the roll becomes greater than that on the concave side. Accordingly, the heat flux flowing toward the inside of the roll is increased. As a result, temperature unevenness is caused and increased, resulting in an increase in roll bending. Namely, roll bending promotes temperature unevenness, which in turn increases roll bending. It is considered that large roll bending is caused by the repetition of such phenomena. The probable reason why roll bending is not infinitely increased but remains nearly unchanged at a certain level is that the difference in bending phase between the upper and lower rolls is decreased due to roll slip.

The reason why center segregation deteriorates due to roll bending is considered as follows. Because the bent roll rotates eccentrically due to thermal deflection of roll, the slab is greatly reduced in thickness by the bent roll when the convex side of roll reaches the slab surface, causing the flow of residual molten steel. This flow might induce the enrichment of solute elements. Center segregation is considered to deteriorate because of the succession of the squeezing of molten steel at the roll position. Moreover, the center segregation at the position where the slab is frequently subjected to reduction due to the attachment of convex side of roll may be locally improved because of the flowing out of enriched molten steel, while at the position where the slab is frequently subjected to lighter reduction due to the attachment of concave side of roll, center segregation may greatly deteriorate because of the inflow of enriched molten steel, thus causing the variation of center segregation in the casting direction.

\subsection{Estimation of Contribution Ratios of Various Mechanical Factors to Center Segregation}

In addition to the results of measurement of roll bending described above, the amount of roll displacement due to other mechanical factors was measured at Kimitsu No. 2 continuous caster, and the amount of slab bulging between rolls was estimated by calculation, thus estimating contribution ratio of each mechanical factor to center segregation from the amount of roll displacement. The contribution ratio was assumed to be the ratio of the slab displacement due to each mechanical factor to the total displacement, where the amount of slab displacement was approximated by the amount of roll displacement. The amount of slab bulging was calculated by Eq. (1) which is an equation for approximating the values calculated by the dynamic bulging analysis model proposed by Matsumiya et al. ${ }^{13)}$ It was confirmed that the amount of bulging calculated by this equation is in good agreement with the value obtained by the dynamic analysis model. The relationship between the amount of bulging calculated by Eq. (1) and roll pitch is shown in Fig. 19. It will be noted that the amount of bulging is below $0.2 \mathrm{~mm}$ when the roll pitch is less than $400 \mathrm{~mm}$.

$$
\delta_{B}=1.893 \times 10^{-3} \frac{l_{P}^{3.3}}{S^{2.85}} P^{1.22} \exp \left(\frac{-5755}{T_{1}+273}\right) \ldots \ldots
$$

where, $\delta_{B}$ : amount of bulging $(\mathrm{mm})$

$$
\begin{aligned}
& S: \text { shell thickness }(\mathrm{mm}) \\
& l_{P}: \text { roll pitch }(\mathrm{mm}) \\
& T_{1}: \text { surface temperature of slab }\left({ }^{\circ} \mathrm{C}\right) \\
& P: \text { static pressure of molten steel }\left(\mathrm{kg} / \mathrm{cm}^{2}\right) .
\end{aligned}
$$

The results of calculation of the contribution ratios of various mechanical factors to center segregation are shown in Fig. 20. If roll bending to be caused during the casting with one-piece rolls of conventional type is 


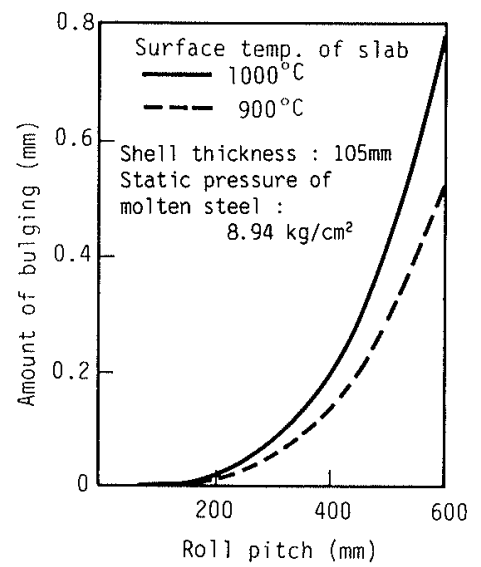

Fig. 19. Relationship between calculated amount of bulging and roll pitch.

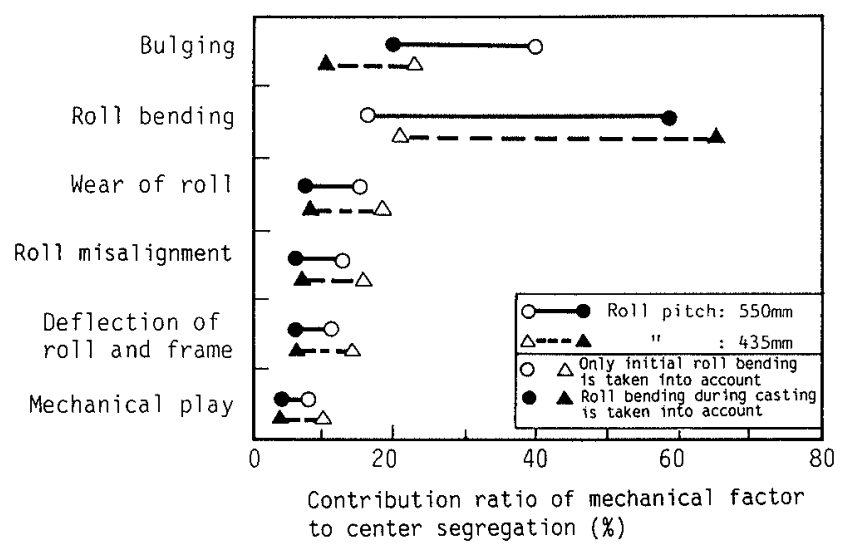

Fig. 20. Contribution ratios of various mechanical factors to center segregation.

neglected, bulging is the largest factor for deterioration of center segregation as has been hitherto reported. If such roll bending is taken into account, however, it is estimated as shown in Fig. 20 that roll bending is the largest factor for deterioration of center segregation even if the roll pitch is as large as $550 \mathrm{~mm}$.

\section{Conclusion}

The influence of roll bending on center segregation was analyzed by conducting tests at continuous casters in commercial operation. As a result, it was clarified that roll bending is caused by temperature unevenness in the roll which in turn results in variations in center segregation in the casting direction. Roll bending can be reduced to less than $0.2 \mathrm{~mm}$ and center segregation can be stably maintained at low level by using divided rolls in the final stage of solidification. According to the results of calculation of the contribution ratio of each mechanical factor to center segregation, the contribution of slab bulging between rolls is relatively small during casting and roll bending was estimated to be the largest factor for deterioration of center segregation in the case of casting employing one-piece rolls of conventional type. Based on these results, it is considered essential for the prevention of center segregation of the slab to prevent roll bending by the use of divided rolls and to reduce slab deformation due to various mechanical factors in a well balanced manner, in addition to compensating solidification shrinkage by taking appropriate measures such as soft reduction in the final stage of solidification.

\section{REFERENCES}

1) T. Kawawa, H. Satoh, S. Miyahara, K. Koyano and H. Nemoto: Tetsu-to-Hagané, 60 (1974), 486.

2) K. Asano, K. Hiromoto and T. Ohashi: Tetsu-to-Hagané, 59 (1973), S82.

3) K. Sasaki, Y. Sugitani and S. Ishimura: Tetsu-to-Hagané, 66 (1980), 43.

4) K. Miyazawa and K. Schwerdtfeger: Arch. Eisenhüttenwes, 52 (1981), No. 11, 415.

5) U. Nashikazu, K. Yasumoto, M. Tokuda and K. Hirakawa: Tetsu-to-Hagané, 60 (1974), S96.

6) I. Katoh, Y. Sugitani, S. Ishimura, T. Adachi and K. Yamada: Tetsu-to-Hagané, 65 (1979), S713.

7) W. R. Irving, A. Perkins and M. G. Brooks: Ironmaking Steelmaking, 11 (1984), No. 3, 152.

8) A. Perkins, M. G. Brooks and R. S. Haleem: Ironmaking Steelmaking, 12 (1985), No. 6, 276.

9) T. Kawawa, H. Satoh, S. Miyahara, K. Koyano and H. Nemoto: Tetsu-lo-Hagané, 60 (1974), 206.

10) K. Miyamura, I. Taguchi and H. Soga: Tetsu-to-Hagané, 69 (1983), A 197.

11) S. Takaishi, T. Komai, K. Noro and Y. Akita: Tetsu-to-Hagané, 60 (1974), 915.

12) S. Ogibayashi, M. Kobayashi, M. Yamada and T. Mukai: ISIJ Int., 31 (1991), 1400.

13) T. Matsumiya, H. Kajioka and Y. Nakamura: Tetsu-to-Hagané, 68 (1982), Al45. 